IZA DP No. 9560

Informal Fee Elimination and Student Performance:

Evidence from The Gambia

Leanne Giordono

Todd Pugatch

December 2015 


\title{
Informal Fee Elimination and Student Performance: Evidence from The Gambia
}

\author{
Leanne Giordono \\ Oregon State University \\ Todd Pugatch \\ Oregon State University \\ and IZA
}

Discussion Paper No. 9560

December 2015

\author{
IZA \\ P.O. Box 7240 \\ 53072 Bonn \\ Germany \\ Phone: +49-228-3894-0 \\ Fax: +49-228-3894-180 \\ E-mail: iza@iza.org
}

Any opinions expressed here are those of the author(s) and not those of IZA. Research published in this series may include views on policy, but the institute itself takes no institutional policy positions. The IZA research network is committed to the IZA Guiding Principles of Research Integrity.

The Institute for the Study of Labor (IZA) in Bonn is a local and virtual international research center and a place of communication between science, politics and business. IZA is an independent nonprofit organization supported by Deutsche Post Foundation. The center is associated with the University of Bonn and offers a stimulating research environment through its international network, workshops and conferences, data service, project support, research visits and doctoral program. IZA engages in (i) original and internationally competitive research in all fields of labor economics, (ii) development of policy concepts, and (iii) dissemination of research results and concepts to the interested public.

IZA Discussion Papers often represent preliminary work and are circulated to encourage discussion. Citation of such a paper should account for its provisional character. A revised version may be available directly from the author. 
IZA Discussion Paper No. 9560

December 2015

\section{ABSTRACT \\ Informal Fee Elimination and Student Performance: Evidence from The Gambia*}

Informal school fees - for uniforms, books, and other supplies - are substantial in developing countries, often several times formal tuition. We evaluate a scholarship program that alleviated informal fees for girls in a subset of Gambian secondary schools. The program is unique because it overlapped with a government policy that had already eliminated formal school fees for girls, allowing for a comparison between program recipients and students who paid no tuition fees but were responsible for other expenses. We analyze the program using difference-in-differences, an identification strategy we support by documenting common pretreatment outcome trends between treated and untreated schools. We find that informal fee alleviation increased female enrollment by $13 \%$ and the share of enrolled students who took the $9^{\text {th }}$ grade exit exam by 11 percentage points. These results highlight the importance of informal fees in secondary school outcomes, even in settings where formal fees have been lifted.

JEL Classification: $\quad 015,121,125$

Keywords: $\quad$ school fee elimination, informal fees, secondary school, gender gap, Gambia

Corresponding author:

Todd Pugatch

School of Public Policy

Oregon State University

303 Ballard Extension Hall

Corvallis, OR 97331

USA

E-mail: todd.pugatch@oregonstate.edu

\footnotetext{
* We thank officials from the Forum for African Women Educationalists in The Gambia (FAWEGAM), the Gambian Ministry of Basic and Secondary Education, the Banjul office of the West African Examinations Council, the World Bank, and World Education (especially Akosua Ampofo, Alpha Bah, Nathalie Lahire, Palamin Mbowe, Yadi Njie-Eribo, Ryoko Tomita Wilcox, and Sherif Yunus Hydara) for sharing their data and institutional knowledge with us. We thank Laura Kawano and seminar participants for helpful comments. We also thank Roberta Nilson for research assistance. This material is based upon work supported by the National Science Foundation Graduate Research Fellowship Program under Grant No. 1314109-DGE.
} 


\section{Introduction}

Although developing countries have made substantial progress in increasing primary school enrollment and completion, secondary school enrollment remains low, particularly for girls. In the least developed countries, gross secondary school enrollment for girls was just $39 \%$ in 2013 (World Bank 2015). Financial barriers are a leading explanation. Programs to reduce school fees have succeeded in increasing secondary enrollment (Banerjee, Glewwe, Powers and Wasserman 2013). Yet even when school fees are eliminated, substantial "informal" fees - for travel, uniforms, textbooks, and other supplies - may remain an obstacle to enrollment and achievement. This paper evaluates the Gambian arm of the Ambassador Girls Scholarship Program (AGSP), which eliminated fees for selected secondary school girls in 41 African countries. Scholarships covered school fees and incidental expenses such as books, uniforms, shoes, bags, and mosquito nets.

The Gambian program is unique because it overlapped with a government program that had already eliminated formal school fees for girls, allowing for a comparison between scholarship recipients and girls who paid no tuition fees but were responsible for other expenses. The institutional setting of the program therefore allows for an assessment of the role of informal fees in student outcomes. Daly (2013) and Daly, Mbenga and Camara (2014) find that such fees are substantial in The Gambia, at more than 5-11 times formal fees in grades 7-9, depending on the measure used. Importantly, budgetary considerations limited the scope of the Gambian AGSP (referred to as the "program" hereafter) to one cohort of students in a subset of secondary schools. This structure allows for comparisons between recipient and non-recipient schools, and within schools based on the timing of program receipt.

We find that informal fee alleviation increased female enrollment in grades $7-8$ by $13 \%$ of the mean. Although these gains did not persist to 9 th grade, students who remained in school were 11 percentage points more likely to take the exam required to continue studies 
through grade 10. Exam performance fell by .09 standard deviations in treated schools, but these declines were absent in the least-advantaged schools. These successes for access and equity highlight the importance of informal fees in secondary school outcomes, even in a setting where formal fees have been lifted.

Informal fees comprise a substantial proportion of household education costs in developing countries. Table A1 reports the ratio of informal/formal fees in selected countries for which there is data. Informal fees are at least as high as formal fees in all cases, and often substantially higher. Excluding a single outlier (Uganda, 2003), informal fees are at least 4.3 times formal fees in all countries listed. In The Gambia, a survey of households with children out of school found financial barriers as the most frequently cited reason for nonenrollment. Many of these families referred specifically to informal fees. Yet in The Gambia and elsewhere, informal fees receive far less attention than formal fees from policymakers and researchers in discussions about student access and performance.

This paper builds on Gajigo (2014) and Blimpo, Gajigo and Pugatch (2015), who found that the Gambian government policy to eliminate formal fees for secondary school girls increased both enrollment and achievement. We evaluate how a smaller-scale effort to lift informal fees among the same student population affected these outcomes. Our work addresses three themes that are gaining prominence among policymakers and researchers seeking to improve education systems in developing countries.

First, after a period of great progress in improving access to primary school, increasing attention is turning to the secondary grades (Banerjee et al. 2013). Second, the persistent gender gap in enrollment and achievement has spurred initiatives targeting girls. A series of recent studies (Kim, Alderman and Orazem (1999a) and Chaudhury and Parajuli (2010) for Pakistan; Filmer and Schady (2008) for Cambodia; Kremer, Miguel and Thornton (2009) for Kenya; Baird, McIntosh and Ozler (2011) for Malawi; and Begum, Islam and Smyth (2012) for Bangladesh, in addition to the evidence from The Gambia previously mentioned) 
examined the effectiveness of fee reductions on girls' secondary school enrollment, with most finding improvement. Other programs focused on improving outcomes for girls have also proved effective, such as school construction in Pakistan (Kim, Alderman and Orazem 1999b) and Burkina Faso (Kazianga, Levy, Linden and Sloan 2013), and providing bicycles in India (Muralidharan and Prakash 2013).

A third strand of the literature focuses on education quality. Despite increasing enrollment, many students in developing countries make little academic progress (Pritchett 2013). Although research has increased our understanding of how financial barriers affect student achievement in primary school (e.g., Lucas and Mbiti 2012), less is known about this relationship at the secondary level (Banerjee et al. 2013). Among the studies cited above on financial barriers and girls' secondary education, only Baird et al. (2011) and Blimpo et al. (2015) examine learning outcomes.

Our work contributes to all three strands of this literature. To our knowledge, this is the first study of the marginal effect of informal fee elimination on secondary school students in a developing country using a credible identification strategy. ${ }^{1}$ This is also the first credibly identified evaluation of the Ambassador Girls Scholarship Program, which provided more than 550,000 scholarships across 41 African countries. ${ }^{2}$ In addition to measuring the effects of informal fee elimination on enrollment, we also quantify its effect on student achievement using administrative data on the universe of scores from a standardized test administered to Gambian 9th graders. This analysis adds to the thin evidence base on the effect on learning outcomes from reducing financial constraints for secondary school girls.

\footnotetext{
${ }^{1}$ We emphasize "marginal effect" because other programs analyzed in the literature, such as conditional cash transfers, may be sufficient to cover informal fees, but these effects are confounded with concurrent alleviation of formal fees. Other studies have also evaluated informal fee reductions for primary school students (e.g., Duflo, Dupas and Kremer 2014).

${ }^{2}$ The document referencing the number of beneficiaries is unclear on whether these are unique students or a measure of student-years (Morgan Borszcz Consulting LLC 2012). Even if the latter, the program reached at least 78,500 students in its seven years of operation, 2004-2011.
} 


\section{Program Description}

The Ambassador Girls Scholarship Program (AGSP), funded by the United States Agency for International Development (USAID), provided scholarships and mentoring to students in 41 countries throughout Africa. World Education, an international non-governmental organization (NGO), administered the program in its 13 recipient West African countries, including The Gambia. In The Gambia, a local NGO (the Forum for African Women Educationalists in the Gambia, or FAWEGAM) implemented the program on behalf of World Education. ${ }^{3}$

The Gambian arm of the program began in 2007 in 12 lower secondary (grades 7-9) schools, which were chosen by FAWEGAM in consultation with the Ministry of Basic and Secondary Education (MoBSE). ${ }^{4}$ The program expanded to 3 more schools when additional funding became available in 2009. At its peak, over 900 girls received the scholarship. All recipient schools were located in Region 2, the education administrative region immediately outside the capital Banjul (Region 1); schools in all other regions (Regions 1 and 3-6) did not participate. Figure 1a shows the location of all schools in the estimation sample (AGSP and non-AGSP). Figure 1b displays only AGSP treatment schools, all located in Region 2, with district (a subregional administrative unit) borders shown.

Since 2004, the Gambian government had eliminated tuition fees for girls in all public secondary schools in Regions 2-6. This policy, known as the girls' scholarship program, had a similar name as our program of interest, but differed in essential features. The government policy was much broader in scope, reaching all girls in grades 7-12 in the program regions. It also covered only formal school fees; girls who benefited from the program were still responsible for all other school expenses, including uniforms, books, travel, etc. By the

\footnotetext{
${ }^{3}$ Program details provided in this section come from Morgan Borszcz Consulting LLC (2012) and personal communications with staff at World Education and FAWEGAM.

${ }^{4}$ We follow the Gambian convention in referring to the 2006-2007 academic year as 2007, to 2007-2008 as 2008 , and so on.
} 
time the AGSP began in 2007, therefore, girls could already attend schools selected for the program tuition-free.

Although program schools were geographically dispersed throughout Region 2, their deliberate selection makes them likely to differ from other schools in many ways. We therefore use an empirical method (difference-in-differences) that allows us to account for idiosyncratic differences among schools. We describe our methodology in greater detail in the next section, and characterize observed differences between schools in Section 4 .

Within program schools, scholarship recipients comprised a subset of a single cohort of female students that entered 7 th grade in 2007. ${ }^{5,6}$ Eligible students were informally identified by, and ultimately selected by, local committees composed of community leaders. Committees were provided with guidance to select students based on need, as indicated by vulnerability to economic disadvantage, orphan status, handicapped status, and/or affected by HIV/AIDS. Recipients who advanced to Senior Secondary School (grades 10-12) continued to receive the scholarship package through 11th grade (2011), when the program ended. The AGSP program operated in six Senior Secondary Schools.

The scholarship package, valued at $\$ 90$ USD per student, included textbooks, notebooks, bed nets, uniforms, shoes, and bags, as well as supplementary mentoring. The scholarship's value far exceeded boys' formal school fees of $\$ 5$ USD for grades 7-9 and $\$ 32$ for grades 10-12 (Daly 2013). Items were delivered as goods, with contents fairly stable over time, although some items may have been fine-tuned. Mentoring activities were more varied, but frequently included extra classes, exam preparation and career guidance; mentors, who were provided

\footnotetext{
${ }^{5}$ Scholarship recipients in the three additional schools added in 2009 were all 9th graders, hence also from this cohort. We consider this set of schools part of the treatment group for all grade 9 outcomes, but part of the control group for grade 7-8 outcomes.

${ }^{6}$ Male students from the same cohort were also added in all program schools in 2008. However, the male program was relatively small, reaching only $20 \%$ of enrolled boys in program schools, compared to more than $85 \%$ of girls. Additionally, the requirement that non-recipient male students pay both formal and informal school fees changes the interpretation of the program's effect for males. Nonetheless, we check outcomes for male students later in the paper.
} 
with a stipend, were frequently selected from among local teachers. The bundling of school materials with mentoring make us unable to disentangle the effect of each when estimating the program effect. However, many Gambian students of modest backgrounds receive similar mentoring; $78 \%$ of 5 th graders report attendance at extra class or tutoring outside school. ${ }^{7}$ The mentoring component of the program could therefore reasonably be considered part of informal fee alleviation rather than an additional component of treatment.

Additionally, while all mentoring activities were targeted to AGSP scholars, many of the activities were likely open to other students. The program intentionally discouraged separation and isolation of scholars from other students, and encouraged sharing of relevant package items and activities, suggesting the possibility of spillover effects for non-scholarship students in AGSP schools. These potential spillovers, as well as the likelihood of systematic differences between recipient and non-recipient students within selected schools, make it appropriate to define treatment at the school rather than student level.

\section{Methodology}

As described in the preceding section, a subset of Gambian secondary schools were selected for the program beginning in 2007. A simple comparison between recipient and non-recipient schools risks bias if the selection criteria include unobserved characteristics related to enrollment or achievement, such as financial need or school quality. As long as these characteristics are not shifting at different rates between treatment and control schools, however, a comparison of changes in outcomes will provide unbiased estimates of program impact even if the levels of school characteristics differ. Using longitudinal data on student enrollment and performance before and after program implementation, we can compare changes in outcomes in recipient and non-recipient schools using a difference-in-differences design. The estimating

\footnotetext{
${ }^{7}$ From a 2012 survey of 26,501 5th graders administered with Gambia National Assessment Test.
} 
equation is:

$$
y_{s t}=\alpha+\beta D_{s t}+\gamma_{s}+\delta_{t}+\epsilon_{s t}
$$

where $y$ is a school-level outcome (such as enrollment or test score) and $D$ is an indicator for whether the program was in school $s$ at time $t .^{8}$ The inclusion of school and time fixed effects ( $\gamma$ and $\delta$, respectively) capture mean outcomes within schools and years, ensuring that the coefficient $\beta$ measures the differential change in outcomes between recipient and non-recipient school-years.

We limit the sample to public schools in Regions 2-6, because all secondary schools in these regions had removed formal school fees for girls by the time of the program's inception. This ensures that within our sample, scholarship recipients differ from female non-recipients only in that the latter must pay for informal school fees. This allows us to interpret the difference-in-differences coefficient $\beta$ as the marginal effect of the program beyond elimination of formal school fees.

The program's effect on enrollment should be positive if some scholarship recipients would not have attended school in the absence of informal fee alleviation. The expected effects for test-taking and test scores are ambiguous, however. If the program identified strong students who otherwise would not have enrolled, or alleviated financial stress for students who would have enrolled anyway, then test-taking and test scores should rise. On the other hand, if the program induced less prepared students to enroll or strained school resources due to larger class sizes, then test-taking levels and average scores could decline.

The identifying assumption of the analysis is that outcome trends in recipient schools would have matched trends in non-recipient schools in the absence of the program. To test

\footnotetext{
${ }^{8}$ Program data record the number of scholarship recipients at a school for each year, but do not identify individual recipients. We therefore run regressions for test scores at the individual level, but define treatment at the school level.
} 
the plausibility of this assumption, we check for differential pre-treatment outcome trends using the following regression:

$$
y_{s t}=\alpha+\beta t+\theta t * D_{s}+\gamma_{s}+\epsilon_{s t}
$$

where the sample is limited to pre-treatment periods (i.e., 2006 or earlier) and $D$ now indicates eventual program receipt. The coefficient $\theta$ captures any differential pre-treatment outcome trend between schools that later receive the program and those that do not; the null hypothesis $\theta=0$ therefore corresponds to the identifying assumption of the differencein-differences estimator.

We cluster all standard errors by school, the unit of treatment, of which there are 106 in the sample.

\section{Data}

Data for the analysis come from several sources. Administrative data on AGSP scholarship distribution by school were made available by World Education, the NGO that managed the program in West Africa on behalf of USAID. Student enrollment totals and school characteristics come from the Education Management Information System (EMIS), an annual census of schools taken by the Gambia Ministry of Basic and Secondary Education (MoBSE). Finally, individual test scores on the Gambia Basic Education Certificate Examination (GABECE, hereafter grade 9 exam), a standardized test taken by all 9th graders, come from the West African Examinations Council (WAEC). Each of these sources is administrative and represents the universe of the relevant units. We merged these data using unique school identifiers.

Formal schooling in The Gambia consists of primary (grades 1-6), lower secondary (grades 
7-9), and senior secondary (grades 10-12). Lower secondary schools are of two types: Basic Cycle Schools (BCS), which include grades 1-9, and Upper Basic Schools (UBS), which include only grades 7-9. Public and private schools exist at all levels, though private schools accounted for only $7 \%$ of lower secondary enrollment at the inception of the program in 2007. The annual school census, available through 2012, includes enrollment levels (total and by gender) and a variety of school characteristics (e.g., school level, public or private, number of teachers, region, etc).

The AGSP data record the number of scholarship recipients in each program school for all years in which the program was active, 2007-2011. Students from 21 public schools, all located in Region 2, were awarded AGSP scholarships, including 4 Basic Cycle Schools (1st9th grade), 11 Upper Basic Cycle Schools (7th-9th grade) and 6 Senior Secondary Schools (10th-12th grade). In this paper, we focus on grades $7-9$, as this is where we expect to see the largest program impacts.

Grade 9 test scores for all students are available from 2003, the first year of the exam, through 2012. The exam tests mastery of the lower secondary curriculum, with students choosing up to 9 subjects, including the required "core" of Math, English, Science, and Social and Environmental Studies. For each student, the data record the student's gender, school, and subject-specific scores. Students wishing to continue to grade 10 must indicate a preference for a senior secondary school and meet that school's minimum aggregate score for admission. Unfortunately, we lack data on student preferences or school admissions criteria. Following the literature, we focus on scores in English and math, which are required subjects for all students. We convert test results to $z$-scores based on the universe of results in a specific year, including Region 1 and private schools, allowing us to interpret the scores relative to the national norm. Even though test scores are available at the individual level, AGSP program data do not identify individual recipients, so we assign a school's treatment status to all students in that school when using student-level data. 
Our estimation sample includes all public lower secondary schools in Regions 2 through 6 from 2003-2012. We exclude Region 1 and private schools (including the lone private school that participated in the program) from the sample because of their ineligibility for the government-funded girls' scholarship program. This sample definition allows us to compare girls in the treatment group, in which AGSP recipients need not pay formal or informal fees, with control group girls who pay informal fees only. We include private schools and Region 1 in later robustness checks.

Figure 2 displays the count of schools by year and AGSP treatment assignment. The number of control group schools grew over time, reflecting expanding secondary enrollment. School-level fixed effects were used throughout the analyses to control for systematic differences between schools.

Table 1 presents summary statistics on the main outcomes considered in the paper, separately for treatment and control schools. Table 1a, which restricts the sample to pretreatment years, reveals that compared to control schools, AGSP schools had higher female enrollment but similar proportions of females enrolled. Similarly, they had a higher number of female grade 9 test-takers than non-AGSP schools, but similar proportions of test-taking females. Students in treated schools performed better in math but slightly worse in English. The disparities shown in the table underscore the need for a method that relies on differences in outcome trends, rather than levels, to estimate the program's impact.

Table 1b includes all school-years, to give a sense of the overall sample sizes and outcome levels in the estimation sample. Table 2 shows more detail on program receipt by grade. In the average AGSP school, nearly 70 girls in 7th and 8th grades received the scholarship, or roughly $85 \%$ of those enrolled. The number of recipients and the program's share of enrolled girls fell in grade 9, suggesting that some recipients dropped out.

Figures 3a to 3h present the mean outcomes experienced each year by AGSP and nonAGSP schools, while Figures 4a and 4b display average test scores each year for females by 
enrollment in AGSP school. The vertical red lines mark the treatment year for each outcome. The data do not display any striking jumps between treatment and control schools in the treatment year, with the possible exception of English scores, which drop sharply in treated schools in 2009 compared to a flat trend in control schools. Although these figures give a picture of the raw data, they may mask important differences that arise when conditioning on factors idiosyncratic to particular schools and years of data. The next section presents results from such a formal analysis.

\section{Results}

\subsection{Pre-treatment trends}

We first examine the validity of our research design before presenting main results. Recall that the identifying assumption behind our difference-in-differences strategy is that outcome trends would have been identical, on average, in treated and control schools in the absence of the program. We cannot test this assumption directly, but can check its plausibility by testing whether outcome trends were parallel between treatment and control schools prior to the introduction of the program. To do so, we run regression (2) using pre-treatment school-years only, with results in Table 3. We examine female enrollment by school in Table 3a, separately for grades 7-9, in both levels (columns 1-3) and as a proportion of school enrollment (columns 4-6). In Table 3b we explore outcomes from the national grade 9 exam, including the number of female test-takers and their proportion (columns 1-2), as well as their scores on math and English (combined and separately) and in the four core subjects (columns 3-6). ${ }^{9}$

\footnotetext{
${ }^{9}$ Because the program was given only to the cohort that entered grade 7 in 2007, the definition of pre-treatment years (and corresponding sample size) varies by outcome. For instance, 2006 is the last pretreatment year for grade 7 enrollment, while 2007 is the last pre-treatment year for grade 8 enrollment. We use all pre-treatment years available for each outcome since 2003, when the grade 9 exam began, in order
} 
Our interest is in whether schools that eventually received the program had different outcome trends before treatment than those that did not, which would be indicated by a significant coefficient on the interaction between eventual program receipt and a linear time trend. This interaction term is not statistically distinguishable from zero for any of the outcomes considered in Table 3. We conclude that the identifying assumption behind our difference-in-differences estimation strategy is sound.

\subsection{Main results}

Table 4 presents results from estimating equation (1), using the same outcomes as the pretreatment trends examined in Table 3. In Table 4a, column (1) we find that the program increased female enrollment in grade 7 by 10.5 students, significant at $5 \%$. This increase is large, representing more than $14 \%$ of the 71.9 females enrolled in 7 th grade in the average school. With 68.4 program recipients in the average treatment school, our estimate implies that $15 \%$ of scholarship recipients would not have enrolled in the absence of informal fee alleviation.

Column (2) finds a similar result for grade 8 enrollment, with an increase of 8.7 female students due to the program. The effect size is nearly $13 \%$ of mean enrollment and significant at 5\%. The program coefficient is no longer positive or significant for grade 9 enrollment in column (3), however, suggesting that enrollment gains did not persist.

Another way to gauge the enrollment effects reported in Table 4a is to compare them with those from formal fee alleviation. Gajigo (2014) finds that eliminating formal fees increased the enrollment rate of secondary school-aged (13-18) females by 10 percentage points. We cannot directly estimate the effect of informal fee alleviation on the enrollment rate for lack of time-varying data on the eligible population. ${ }^{10}$ However, we can compare our estimates to maximize statistical power. We run regressions for test scores at the student level, with all others at the school level.

${ }^{10}$ Gajigo (2014) uses successive waves of the Gambia Integrated Household Survey, which is sensible given 
of enrollment increases to the relevant population from the 2003 Gambia Census. Villages closest to AGSP schools averaged 288 girls aged 13-18 in 2003. Dividing the sum of our point estimates for grades 7-9 by this amount yields an estimated increase of 4.1 percentage points in the female enrollment rate. Disregarding the insignificant point estimate for grade 9 increases the estimate to 6.7 percentage points. Although these (admittedly crude) estimates are smaller than those for formal fee alleviation, they must be interpreted as the marginal effect of informal fee alleviation after formal fees have already been eliminated. This is a notable and novel finding in the literature on financial barriers to schooling.

Despite gains in enrollment in the early secondary grades, the program did not increase the proportion of girls enrolled in grades 7-9 (Table 4a, columns 4-6). ${ }^{11}$ The first two columns of Table $4 \mathrm{~b}$ show that the program also failed to increase the number or proportion of female students taking the grade 9 exam, echoing the findings for grade 9 enrollment. Point estimates for all test scores considered are negative (columns 3-6), with statistically significant declines of .09 standard deviations for math and English combined and for English separately. These declines suggest that reductions in school quality in response to the program, such as inducing less prepared students to enroll or placing a strain on school resources, outweighed any quality increases, such as stress relief from easing financial constraints or the mentoring provided by the program. We explore these issues later in the paper.

The average effects presented in Table 4 may mask differences across types of students, particularly given the program's targeting of the most needy. Although the enrollment and exam data lack information on individual student characteristics, we can look for heterogeneity in treatment effects by observable characteristics of schools or their catchment areas.

the nearly national scale of formal fee alleviation. In our case, the small number of schools receiving the program do not leave sufficiently large samples in the household survey data for reliable estimates. Also, the surveys fail to report the grade level of enrollment, making it difficult to match respondents with the lone cohort that received the program.

${ }^{11}$ This discrepancy is reconciled by positive, but not statistically significant, point estimates for male enrollment. We find no statistically significant effects of the program on males for enrollment or test scores; see Table A3. 
In Table 5, we interact the program dummy with a series of predetermined characteristics that proxy for the socioeconomic status of students at a school. These characteristics include the distance from the school to the main road, the adult illiteracy rate, and the percentage of population with electricity access, where the latter two are village-level aggregates from the 2003 Gambia Census matched to the nearest school. ${ }^{12}$ In each case, we create a dummy variable for whether the school's value lies above the median.

For grades 7-8, we find no statistically significant coefficients on any of the interaction terms between the program and these characteristics (columns 1-6), indicating that the enrollment gains in these grades were widely shared. For grade 9 , however, we find that the most distant schools and those located in villages with the highest illiteracy enrolled 19 more students due to the program than their less distant or more literate counterparts. Although these differences were not large enough to make the overall treatment effect (reported at the bottom of the table) at these schools significantly positive, they nonetheless suggest that less-advantaged schools had more success in keeping scholarship recipients enrolled through 9th grade.

Similarly, in column (10) we find that the test score decline for math and English did not occur at more distant schools. Schools that are further away impose larger travel costs on students, but no travel allowances were provided with scholarships. If students enroll only if their expected gains would offset the additional cost of travel, they may be of higher quality. Similarly, column (12) shows that test score declines were concentrated in schools with the highest electricity access. In these better-off areas, the marginal student induced to enroll might have lower expected gains, and hence be of lower quality. Taken together, the results in Table 4 speak to the program's success in improving outcomes in the least advantaged schools.

\footnotetext{
${ }^{12}$ Gambian policymakers consider distance from the main road a marker of the challenges facing a school, and use this measure to determine "hardship" salary bonuses for primary school teachers (Pugatch and Schroeder 2014b, Pugatch and Schroeder 2014a).
} 


\subsection{Student sorting and school quality}

In addition to influencing enrollment and achievement, the scholarship may also have important effects on how students choose among schools and on school quality. Given that scholarship receipt did not increase enrollment one for one, a natural follow-up question is whether the program changed private school enrollment. Some public school students may have exited to private schools in response to an influx of scholarship recipients. On the other hand, some scholarship students may have attended private schools in the absence of the program, or induced non-scholarship students to stay because of the (often shared) resources they brought to school. To explore this, we define the district as the relevant level of public-private school competition, and look for changes in private enrollment according to a district's program presence. ${ }^{13}$

In Table 6, Panel A, we define treatment as a dummy for whether any school in the district receives the program. ${ }^{14}$ For grades $7-8$, we find decreases in female private school enrollment of roughly the same magnitude as the increases found at the school level in Table 4, although the estimates are not statistically significant. For grade 9, we find a decrease of 11.9 female students in treated districts, significant at 1\%. In columns (5)-(6), we also find losses in private schools' share of female enrollment in treated districts, of 1-2 percentage points over a low base. Although we do not know if any of the students leaving private schools received scholarships or otherwise switched to program schools, it appears that the scholarship made private schools less attractive. ${ }^{15}$

Returning our attention to public schools, the program may have altered student composition, not merely quantity. The test score declines found in Table 4 suggest that scholarship

\footnotetext{
${ }^{13}$ This specification follows the market-level approach of Hsieh and Urquiola (2006) and Lucas and Mbiti (2012).

${ }^{14}$ In these regressions we cluster standard errors by district, of which there are 35 in the sample.

${ }^{15}$ In Table 6, Panel B, we define treatment as the share of public school enrollment in program schools, a more nuanced measure of the program's influence on the public system in a district. Point estimates using this alternate measure of treatment are similar in magnitude but less precise than in Panel A.
} 
students may be negatively selected relative to their peers. However, we fail to find evidence of this negative selection along one dimension of student quality, grade repetition. In Table 7a we find no changes in the level (columns 1-3) or share (columns 4-6) of female students who are repeating a grade. ${ }^{16}$

Table $7 \mathrm{~b}$ looks for changes in the composition of students who take the 9 th grade exam. In column (1), we find that the program increased the proportion of 9th graders taking the exam by 11 percentage points. Because the exam is required to continue one's schooling, this shift reflects expanded student ambitions due to the program. These students also did not reduce their effort on the exam, as shown in the remaining columns. We find no changes in the number of subjects taken, number of subjects for which the student registered but was absent, or in the number or share of easy subjects taken (where we define "easy" as a subject with an above-median passing rate in the pre-treatment data). Even though the program failed to increase the number of students persisting to 9th grade, the increase in test-taking among those who remained provides additional evidence of the beneficial effects of informal fee alleviation.

When describing the program's components earlier in the paper, we touched on the additional resources provided to students, and by extension to their schools. Yet these improvements in school quality might be counterbalanced by increased demands on school resources due to the program. We look for such changes in school quality in Table 8, using data on teacher personnel within a school. In addition to overall teaching resources, we are particularly interested in changes in female teachers. Evidence suggests that girls learn more effectively from female teachers (Dee 2005, Muralidharan and Sheth 2013). In The Gambia, teaching is a male-dominated profession, particularly in the secondary grades (in

\footnotetext{
${ }^{16} \mathrm{~A}$ related question is whether the program increases the presence of repeaters the following year. For instance, do more girls repeat 7th grade in 2008 if that school's 7th grade cohort received the program in 2007? We find no relationship between treatment and grade repetition one year later for any of the measures considered in Table 7a. Results not shown but available upon request.
} 
our data, just $17 \%$ of teachers are female at the average school), making female teachers a scarce resource.

Importantly, the data do not distinguish the grade(s) taught by each teacher, leaving us with only an overall measure of teaching resources at a school. With this caveat in mind, in Panel A, column (1) we find that the number of teachers at a school decreased by 4.3 in response to the program. Column (2) reveals that 1.7 of these teachers were female. This reduced the share of a school's teachers who are female by 4 percentage points (column 3 ) from an already low average. Gains in student enrollment combined with decreases in the teaching corps led to an increase of 6.9 students per teacher (column 4), though this effect attenuates to 2.8 when including primary enrollment in schools that pool grades 1-9.

In sum, Panel A provides clear evidence of declines in school quality due to the program, although we cannot say why teachers - particularly females - left schools when the program entered. ${ }^{17}$ Adjustments to teacher personnel can be slow, such that treated schools seeking to reverse this teaching deficit may not be able to do so until after the program cohort has left the school. We consider this possibility in Panel B, where we redefine treatment to be a dummy for all years since the program began at a school, even if no scholarship recipients remain. Using this alternate measure of treatment, we find that program schools increased their teachers by roughly the same magnitudes as the losses documented in Panel A. Although these gains did not occur until after program recipients had left, these results show that schools at least succeeded in avoiding any long-term quality declines due to the program. $^{18}$

\footnotetext{
${ }^{17}$ Inquiries to government and NGO officials yielded no additional information about our findings.

${ }^{18}$ We also consider whether program effects are related to school quality by interacting treatment with the same measures of teaching resources as Table 8. We use pre-treatment (2003-2006) school averages to avoid endogenous school quality responses due to unobserved factors correlated with program impact. We find that enrollment increases in grades 7-8 were greatest in schools with more female teachers, both in levels and as a share of all teachers at a school. See Table A2.
} 


\subsection{Robustness checks}

In this subsection we check the robustness of our main results on enrollment and achievement using a series of alternate specifications and sample definitions. In Table 9, column (1) we repeat our baseline estimates from Table 4 for reference. Column (2) of Table 9 re-specifies equation (1) in first differences, which may be better suited to detect short-term treatment effects than our fixed effects specification (McKinnish 2008). Point estimates are less precise than column (1), but similar in magnitude.

Another concern with our fixed-effects specification is that if schools are selected on idiosyncratic outcome trends, then our estimates might conflate these trends with the treatment effect. For instance, if schools that had recently performed particularly well in enrolling girls were more likely to be selected for the program, then our specification might be biased in favor of finding an enrollment effect. To some extent we have already ruled this out by demonstrating the lack of differential pre-treatment trends by program status in Table 3, but we go a step further by augmenting regression (1) with school-specific time trends. Results, shown in Table 9, column (3), are largely in line with baseline estimates.

Because not all female students within the treated cohort received the scholarship in program schools, we might expect to see larger treatment effects in schools with a higher proportion of recipients among the enrolled. Our baseline specification, which measures the program as a binary variable, would not detect such differences. In column (4), we redefine treatment as the proportion of enrolled females receiving the scholarship within the treated cohort. ${ }^{19}$ Using this continuous measure of treatment, the program coefficient may be interpreted as the effect of shifting from a control school (with treatment intensity of 0) to a school in which all girls in the cohort receive the scholarship (treatment intensity of

\footnotetext{
${ }^{19}$ We use the number of scholarship recipients in the initial program year (grade 7 or 9) divided by the previous year's enrollment in that grade, for all outcomes, in order to minimize concerns about endogenous adjustments to program intensity over time based on student performance.
} 
1). Again, results are similar in magnitude to the binary version of treatment, although test score results lose statistical significance. The close correspondence between the coefficients on the binary and continuous versions of treatment is not surprising, given that the vast majority of enrolled girls in treated schools received the scholarship.

The remaining columns of Table 9 use alternate sample definitions. In column (5), we include private schools in the sample, to capture any spillovers in program effects between public and private schools (Hsieh and Urquiola 2006). Column (6) includes Region 1 for similar reasons. Results are similar to the baseline in both cases.

Because all program schools are in Region 2, including schools from Regions 3-6 as controls risks introducing a large collection of dissimilar observations. We therefore include only schools from Region 2 in column (7), with the region's private schools also included in column (8). ${ }^{20}$ Results remain similar in magnitude to the baseline, with point estimates of grade 7 enrollment gains even larger than before (though not statistically different).

Finally, column (9) extends the enrollment data back to 1998, the earliest year available (exam data do not begin until 2003). Point estimates are again similar to the baseline, though less precise.

Overall, the main results are robust to a battery of checks, increasing our confidence in the initial estimates of program impact.

\section{Conclusion}

This paper has evaluated the impact of a scholarship program that alleviated informal school fees for girls in a subset of Gambian secondary schools. A unique feature of the program was its overlap with a government policy that eliminated formal fees for secondary school girls, allowing us to estimate the marginal effect of informal fee alleviation on student outcomes.

\footnotetext{
${ }^{20}$ The number of schools - and therefore clusters - remains at least 39 in these specifications, justifying continued use of clustered standard errors based on asymptotic theory.
} 
Our difference-in-differences identification strategy relies on parallel paths for treated and control schools in the absence of the program, an assumption we support by documenting common outcome trends in the pre-treatment period. We find that the program increased female enrollment in grades 7-8 by 8-10 students per school, or $13-14 \%$ of the mean.

Not all of our results are encouraging, however. We find decreases in school quality, such as increased pupil-teacher ratios, suggesting that the inflow of students strained school resources. We also find that the program led to a decline in female test scores of .09 standard deviations. These results seem to support the contention of Banerjee, Cole, Duflo and Linden (2007, p. 1236), who wrote, "Ironically, the difficulty in improving the quality of education may in part be a by-product of the success in getting more children to attend school."

Closer inspection reveals a more nuanced picture, however. Test scores in the least advantaged schools did not fall. Girls who remained in 9 th grade were 11 percentage points more likely to take the exit exam, without exerting less effort, demonstrating increased ambitions. These findings suggest that the tradeoff between school access and quality is not quite so stark, at least in the present context. ${ }^{21}$

More broadly, our results point to the importance of informal fees in shaping education demand and the school environment in developing countries. In recent years, policymakers and external donors have placed greater emphasis on easing financial constraints on human capital investment by reducing formal school fees, and justifiably so. This study suggests that informal fees, which are often several times greater, also deserve increasing attention.

\footnotetext{
${ }^{21}$ The lack of a clear tradeoff between access and achievement in Gambian secondary schools was also a central conclusion of Blimpo et al. (2015).
} 


\section{References}

Baird, Sarah, Craig McIntosh, and Berk Ozler, "Cash or Condition? Evidence from a Cash Transfer Experiment," Quarterly Journal of Economics, November 2011, 126 (4), 1709-1753.

Banerjee, Abhijit V., Paul Glewwe, Shawn Powers, and Melanie Wasserman, "Expanding Access and Increasing Student Learning in Post-Primary Education in Developing Countries: A Review of the Evidence," April 2013.

, Shawn Cole, Esther Duflo, and Leigh Linden, "Remedying Education: Evidence from Two Randomized Experiments in India," Quarterly Journal of Economics, 2007, 122 (3), 1235-1264.

Begum, Lutfunnahar, Asadul Islam, and Russell Smyth, Girls' education, stipend programs and the effects on younger siblings' education, IZA Working Paper, 2012.

Blimpo, Moussa, Ousman Gajigo, and Todd Pugatch, "Financial Constraints and Girls' Secondary Education: Evidence from School Fee Elimination in the Gambia," SSRN Scholarly Paper ID 2655078, Social Science Research Network, Rochester, NY September 2015 .

Chaudhury, Nazmul and Dilip Parajuli, "Conditional Cash Transfers and Female Schooling: The Impact of the Female School Stipend Programme on Public School Enrolments in Punjab, Pakistan," Applied Economics, November 2010, 42 (28-30), 3565-3583.

Daly, Angela, "Barriers to participation and retention," Prepared for Gambia Ministry of Basic and Secondary Education March 2013.

__ , Basiru Mbenga, and Alpha Camara, "Barriers to participation and retention: engaging and returning out of school children in the Gambia," Education 3-13, June 2014, pp. 1-16.

Dee, Thomas S., "A Teacher like Me: Does Race, Ethnicity, or Gender Matter?," The American Economic Review, 2005, 95 (2), 158-165.

Deininger, Klaus, "Does cost of schooling affect enrollment by the poor? Universal primary education in Uganda," Economics of Education review, 2003, 22 (3), 291-305.

Duflo, Esther, Pascaline Dupas, and Michael Kremer, "Education, HIV, and early fertility: Experimental evidence from Kenya," Technical Report, National Bureau of Economic Research 2014.

Education Watch, "The Impact of Informal School Fees on Family Expenditure," Technical Report October 2007. 
Filmer, Deon and Norbert Schady, "Getting Girls into School: Evidence from a Scholarship Program in Cambodia," Economic Development and Cultural Change, April 2008, 56 (3), 581-617.

Gajigo, Ousman, "Closing the education gender gap: estimating the impact of girls' scholarship program in The Gambia," Education Economics, 2014, (ahead-of-print), 1-22.

Hsieh, Chang-Tai and Miguel Urquiola, "The effects of generalized school choice on achievement and stratification: Evidence from Chile's voucher program," Journal of public Economics, 2006, 90 (8), 1477-1503.

Kattan, Raja Bentaouet and Nicholas Burnett, User Fees in Primary Education, The World Bank 1818 H Street, NW Washington, DC 20433 USA, July 2004.

Kazianga, Harounan, Dan Levy, Leigh L. Linden, and Matt Sloan, "The Effects of 'GirlFriendly' Schools: Evidence from the BRIGHT School Construction Program in Burkina Faso," American Economic Journal: Applied Economics, July 2013, 5 (3), 41-62.

Kim, Jooseop, Harold Alderman, and Peter F. Orazem, "Can Private School Subsidies Increase Enrollment for the Poor? The Quetta Urban Fellowship Program," World Bank Economic Review, September 1999, 13 (3), 443-465.

, and _ _ , "Evaluation of the Balochistan Rural Girls' Fellowship Program-Will rural families pay to send girls to school?," 1999.

Kremer, Michael, Edward Miguel, and Rebecca Thornton, "INCENTIVES TO LEARN," The Review of Economics and Statistics, August 2009, 91 (3), 437-456.

Lincove, Jane Arnold, "Determinants of schooling for boys and girls in Nigeria under a policy of free primary education," Economics of Education Review, 2009, 28 (4), 474-484.

Lucas, Adrienne M. and Isaac M. Mbiti, "Access, Sorting, and Achievement: The Short-Run Effects of Free Primary Education in Kenya," American Economic Journal: Applied Economics, October 2012, 4 (4), 226-253.

McKinnish, Terra, "Panel data models and transitory fluctuations in the explanatory variable," Advances in Econometrics, 2008, 21, 335-358.

Morgan Borszcz Consulting LLC, "Building on Investments in Local Capacity: Reflections on the Ambassadors Girls Scholarship Program," Technical Report February 2012.

Muralidharan, Karthik and Ketki Sheth, "Bridging Education Gender Gaps in Developing Countries: The Role of Female Teachers," Working Paper 19341, National Bureau of Economic Research September 2013.

and Nishith Prakash, "Cycling to School: Increasing Secondary School Enrollment for Girls in India," Technical Report, National Bureau of Economic Research 2013. 
Pritchett, Lant, The Rebirth of Education: Schooling Ain't Learning, Washington, D.C: Center for Global Development, October 2013.

Pugatch, Todd and Elizabeth Schroeder, "Incentives for teacher relocation: Evidence from the Gambian hardship allowance," Economics of Education Review, August 2014, 41, 120-136.

and __ , "Teacher Pay and Student Performance: Evidence from the Gambian Hardship Allowance," IZA Discussion Paper 8621, Institute for the Study of Labor (IZA) November 2014.

Wiener, Karen, "School Fee Abolition: Parents' Perspectives," Technical Report, USAID 2010.

World Bank, "World Development Indicators," Technical Report, World Bank 2015. 
Figure 1: Program Maps

(a) Gambia AGSP and non-AGSP Schools

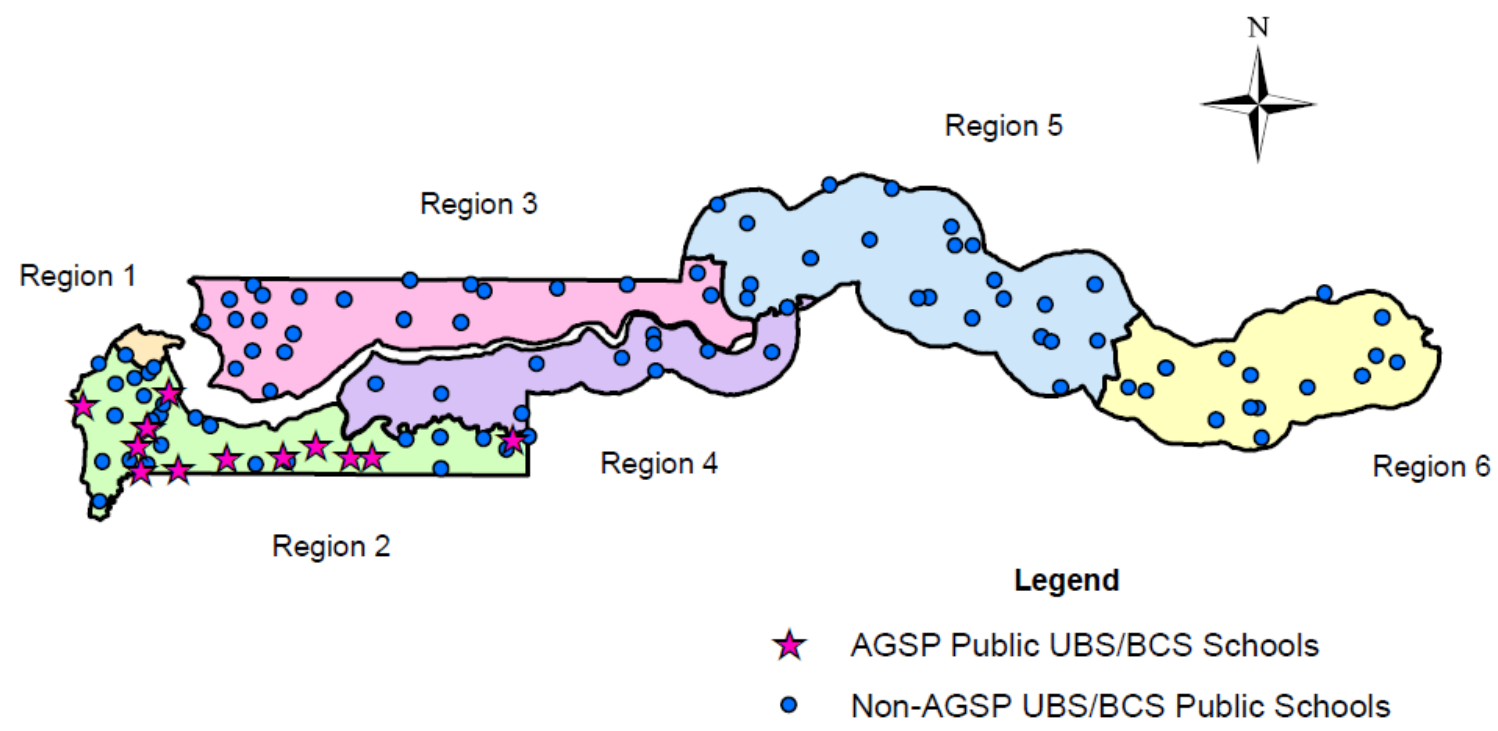

(b) Region 2 AGSP Schools

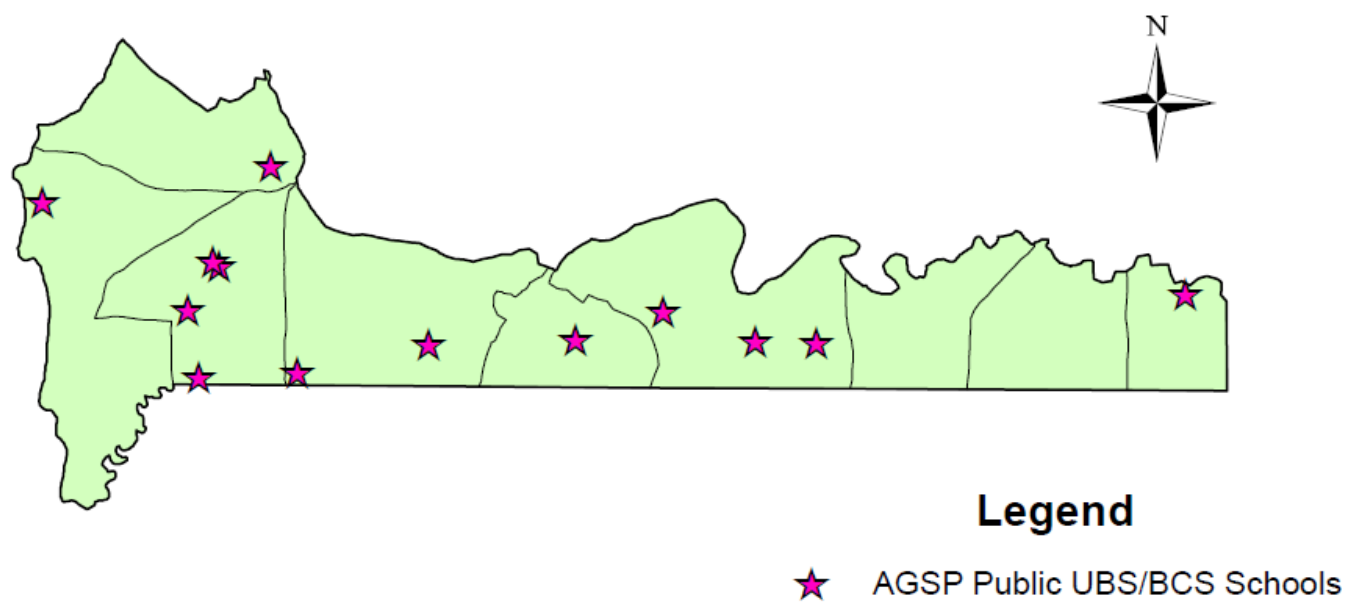


Figure 2: Count of UBS/BCS Schools by AGSP Assignment

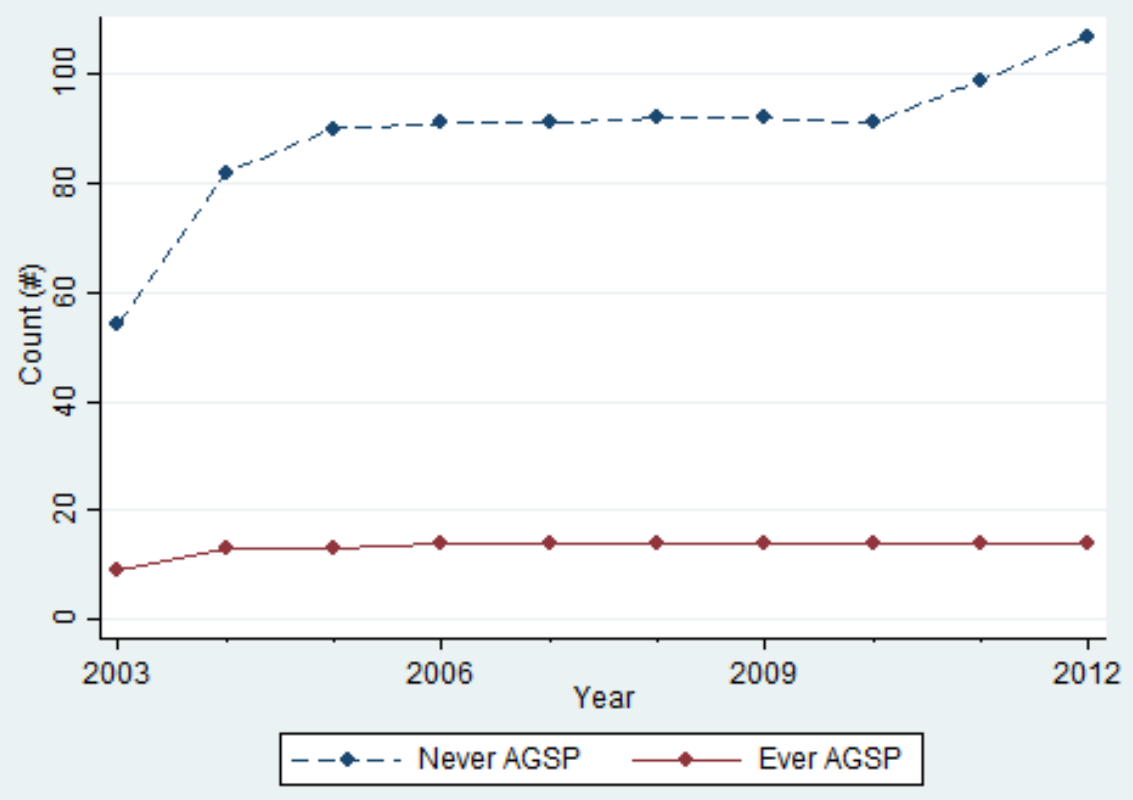




\section{Figure 3: School Outcomes by AGSP Assignment}

(a) Grade 7 Female Enrollment

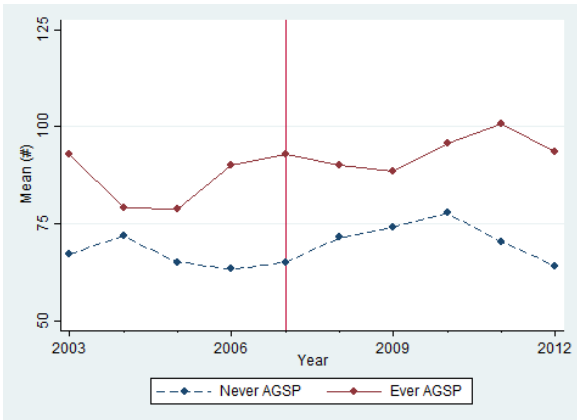

(c) Grade 9 Female Enrollment

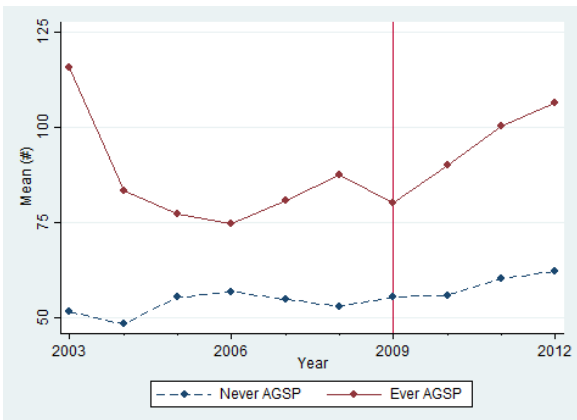

(e) Grade 7 Female Enrollment (\%)

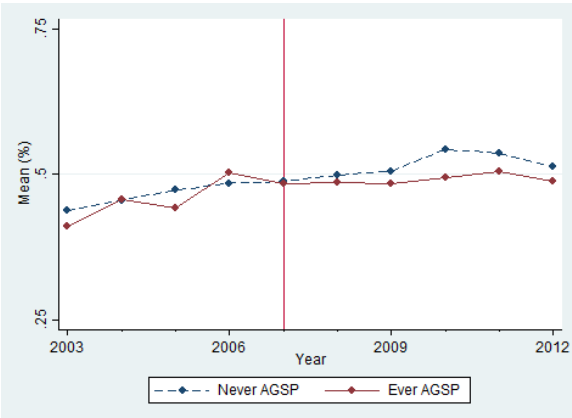

(g) Grade 9 Female Enrollment (\%)

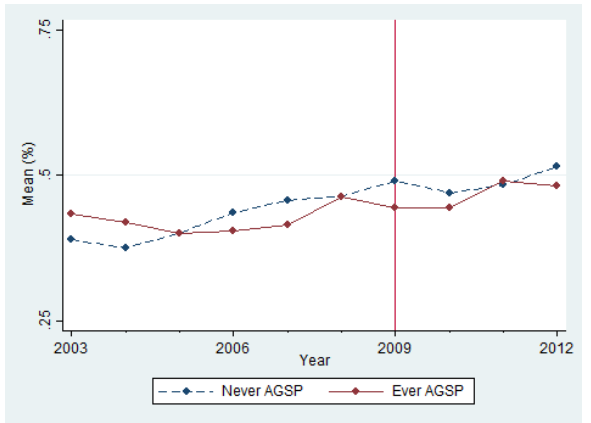

(b) Grade 8 Female Enrollment

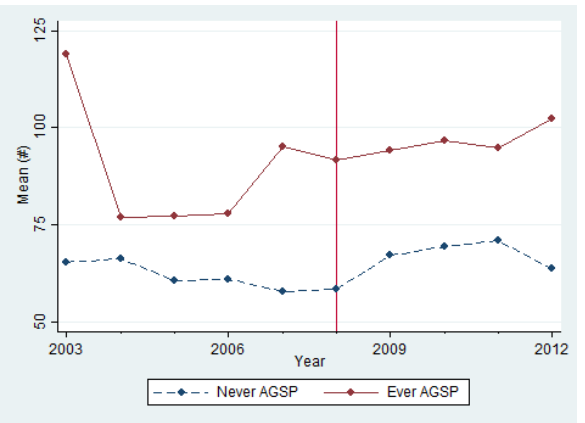

(d) Grade 9 Female Test-takers

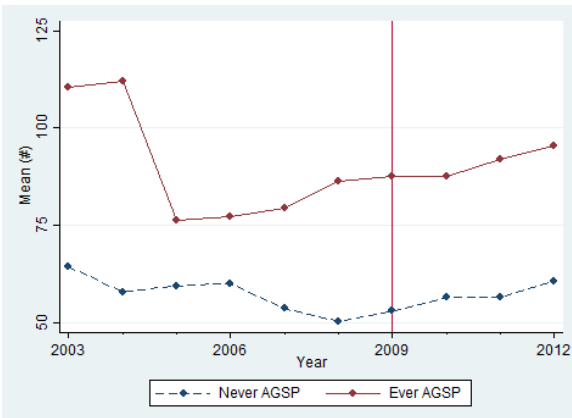

(f) Grade 8 Female Enrollment (\%)

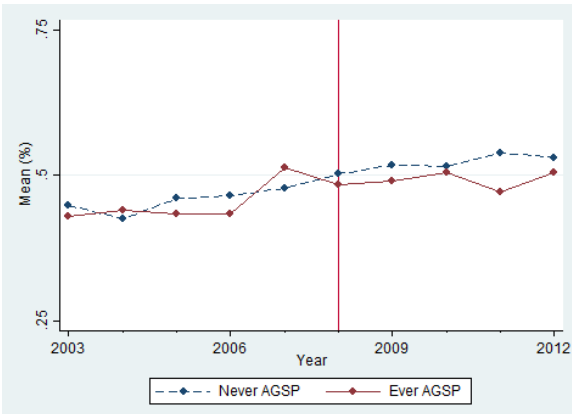

(h) Grade 9 Female Test-takers (\%)

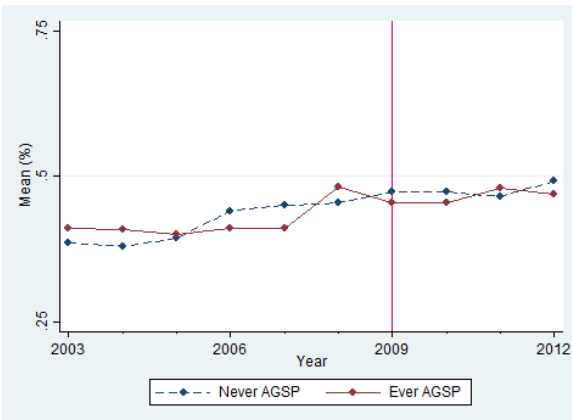


Figure 4: Student Outcomes by AGSP Assignment

(a) Mean Female Math Test Scores

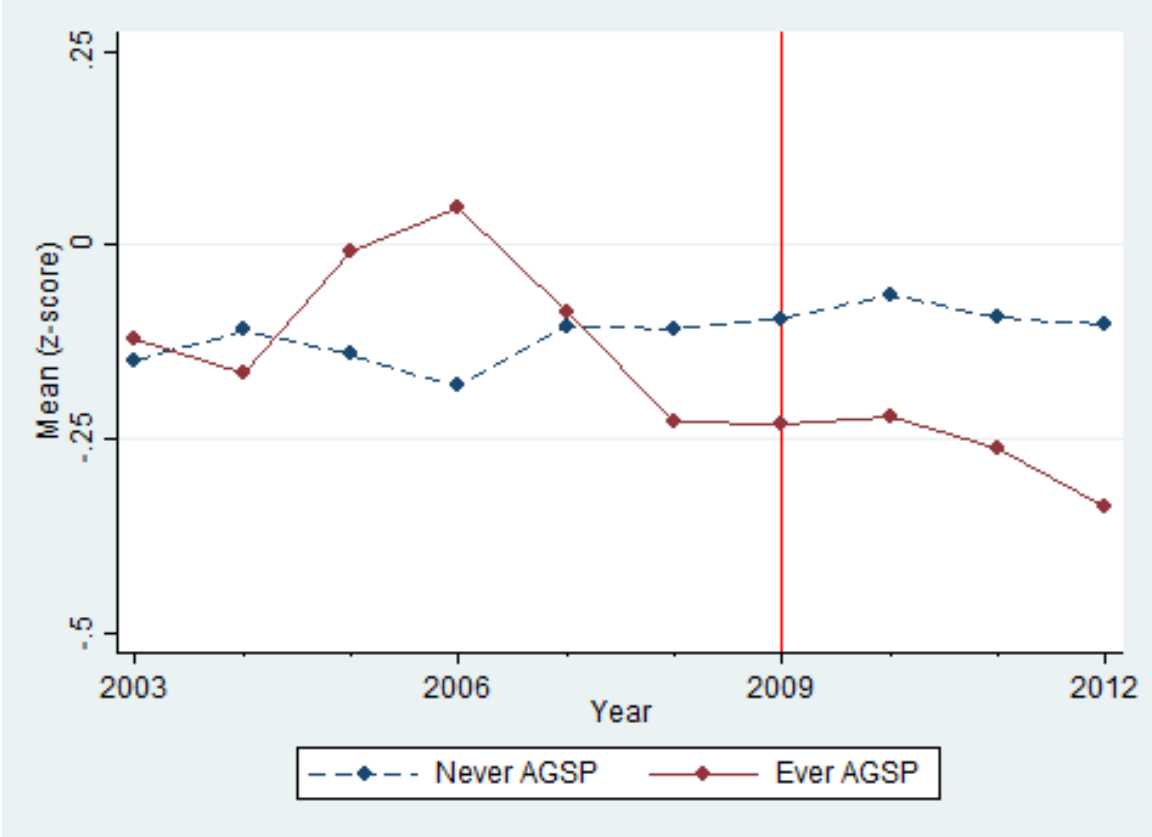

(b) Mean Female English Test Scores

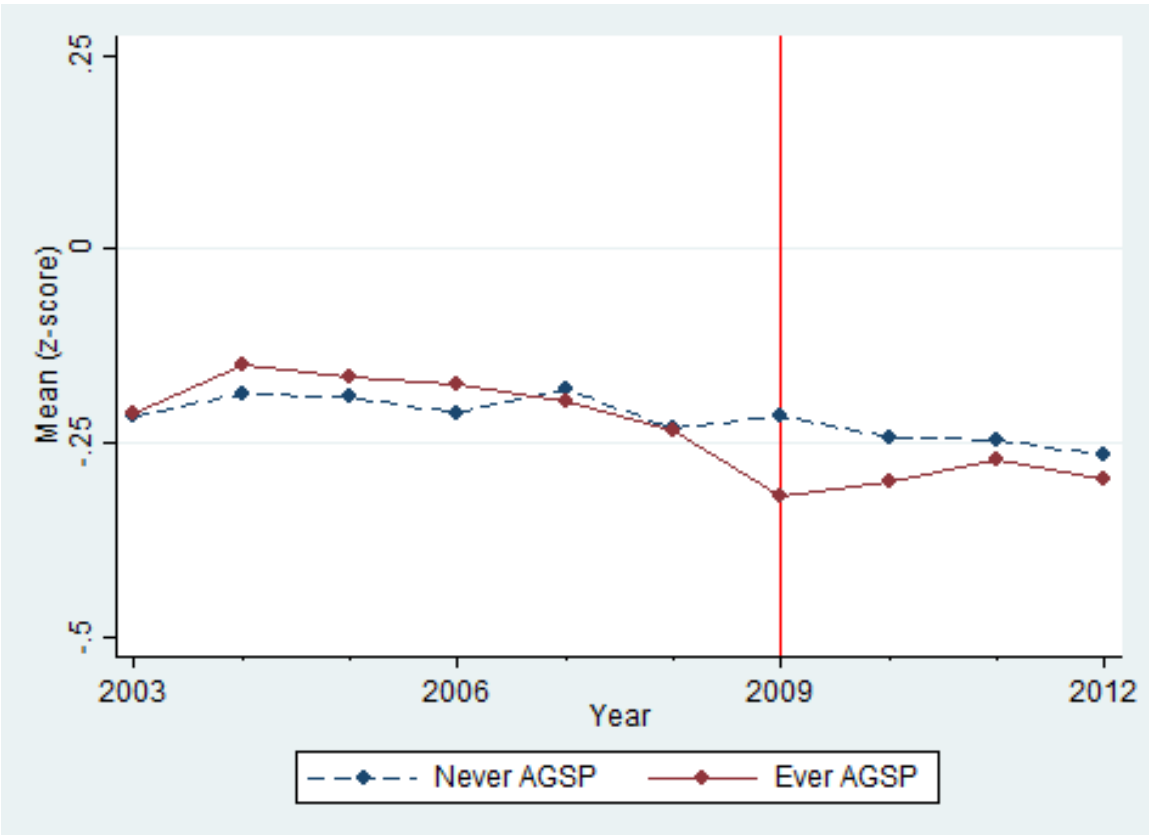


Table 1: Non-AGSP and AGSP Outcomes

(a) Pre-treatment Periods Only

\begin{tabular}{|c|c|c|c|c|c|c|c|}
\hline & \multicolumn{3}{|c|}{ Never AGSP } & \multicolumn{3}{|c|}{ Ever AGSP } & \multirow{2}{*}{$\begin{array}{c}\text { Difference } \\
(7)\end{array}$} \\
\hline & $\begin{array}{l}\mathrm{N} \\
(1)\end{array}$ & $\begin{array}{l}\text { Mean } \\
(2)\end{array}$ & $\begin{array}{c}\text { Std Dev } \\
(3)\end{array}$ & $\begin{array}{l}\mathrm{N} \\
(4)\end{array}$ & $\begin{array}{c}\text { Mean } \\
(5)\end{array}$ & $\begin{array}{c}\text { Std Dev } \\
(6)\end{array}$ & \\
\hline \multicolumn{8}{|c|}{ Female Enrollment } \\
\hline Grade 7 & 317 & 66.8 & 57.7 & 49 & 84.8 & 56.7 & $-17.96^{* *}$ \\
\hline Grade 8 & 317 & 63.1 & 58.9 & 49 & 85.1 & 54.9 & $-21.95^{* * *}$ \\
\hline Grade 9 & 317 & 53.3 & 62.9 & 49 & 85.1 & 60.5 & $-31.8 * * *$ \\
\hline \multicolumn{8}{|c|}{ Female Enrollment (\%) } \\
\hline Grade 7 & 314 & 0.47 & 0.09 & 49 & 0.46 & 0.07 & 0.01 \\
\hline Grade 8 & 309 & 0.45 & 0.10 & 49 & 0.43 & 0.05 & 0.02 \\
\hline Grade 9 & 279 & 0.40 & 0.11 & 44 & 0.41 & 0.07 & -0.01 \\
\hline \multicolumn{8}{|c|}{ Female Test-takers } \\
\hline Grade 9 & 268 & 60.2 & 60.5 & 44 & 90.9 & 48.7 & $-30.73^{* * *}$ \\
\hline Grade $9(\%)$ & 268 & 0.40 & 0.09 & 44 & 0.41 & 0.06 & 0.004 \\
\hline \multicolumn{8}{|c|}{ Female Test Scores } \\
\hline Math & 15,740 & -0.15 & 0.61 & 3,948 & -0.06 & 0.81 & $-0.09 * * *$ \\
\hline English & 15,745 & -0.19 & 0.66 & 3,946 & -0.17 & 0.67 & $0.02^{*}$ \\
\hline
\end{tabular}

(b) All Time Periods

\begin{tabular}{|c|c|c|c|c|c|c|c|}
\hline & \multicolumn{3}{|c|}{ Never AGSP } & \multicolumn{3}{|c|}{ Ever AGSP } & \multirow{2}{*}{$\begin{array}{c}\text { Difference } \\
(7)\end{array}$} \\
\hline & $\begin{array}{l}\mathrm{N} \\
(1)\end{array}$ & $\begin{array}{l}\text { Mean } \\
(2)\end{array}$ & $\begin{array}{l}\text { Std Dev } \\
\text { (3) }\end{array}$ & $\begin{array}{l}\mathrm{N} \\
(4)\end{array}$ & $\begin{array}{c}\text { Mean } \\
(5)\end{array}$ & $\begin{array}{l}\text { Std Dev } \\
(6)\end{array}$ & \\
\hline \multicolumn{8}{|c|}{ Female Enrollment } \\
\hline Grade 7 & 889 & 69.1 & 59.1 & 133 & 90.4 & 67.2 & $-21.24^{* * *}$ \\
\hline Grade 8 & 889 & 64.1 & 58.0 & 133 & 91.9 & 66.3 & $-27.76^{* * *}$ \\
\hline Grade 9 & 889 & 55.7 & 59.5 & 133 & 88.7 & 65.4 & $-32.95^{* * *}$ \\
\hline \multicolumn{8}{|c|}{ Female Enrollment (\%) } \\
\hline Grade 7 & 886 & 0.50 & 0.09 & 133 & 0.48 & 0.07 & 0.02 \\
\hline Grade 8 & 871 & 0.49 & 0.10 & 133 & 0.47 & 0.07 & 0.02 \\
\hline Grade 9 & 834 & 0.46 & 0.11 & 127 & 0.44 & 0.07 & 0.01 \\
\hline \multicolumn{8}{|c|}{ Female Test-takers } \\
\hline Grade 9 & 807 & 56.9 & 55.6 & 127 & 89.1 & 59.5 & $-32.26 * * *$ \\
\hline Grade $9(\%)$ & 807 & 0.45 & 0.10 & 127 & 0.44 & 0.07 & 0.01 \\
\hline \multicolumn{8}{|c|}{ Female Test Scores } \\
\hline Math & 44,635 & -0.11 & 0.72 & 10,979 & -0.17 & 0.69 & $0.06^{* * *}$ \\
\hline English & 44,639 & -0.22 & 0.71 & 11,122 & -0.24 & 0.67 & $0.02^{* * *}$ \\
\hline
\end{tabular}

Unit of observation is school-year for all variables excepts test scores, which use student records. Sample includes public AGSP school and all public non-AGSP schools in Regions $2-6 .{ }^{*}$ significant at $10 \%$; $* *$ significant at $5 \%$; $* * *$ significant at $1 \%$. 
Table 2: AGSP School Characteristics

\begin{tabular}{l|c|c|c}
\hline \hline & \multicolumn{3}{|c}{ Ever AGSP: Treatment Years Only } \\
& $\begin{array}{c}\text { N } \\
\text { Mean }\end{array}$ & $\begin{array}{c}\text { Std Dev } \\
(1)\end{array}$ \\
& & $(2)$ & $(3)$ \\
\hline Female Enrollment & & & \\
Grade 7 & 11 & 81.6 & 66.6 \\
Grade 8 & 11 & 80.4 & 65.3 \\
Grade 9 & 14 & 79.9 & 63.2 \\
Female Recipients & & & \\
Grade 7 & 11 & 68.4 & 29.5 \\
Grade 8 & 11 & 69.7 & 29.7 \\
Grade 9 & 14 & 62.4 & 35.1 \\
Female Recipients (\%) & & & \\
Grade 7 & 11 & 0.84 & 0.36 \\
Grade 8 & 11 & 0.87 & 0.36 \\
Grade 9 & 13 & 0.74 & 0.19 \\
\hline \hline
\end{tabular}

Sample includes public AGSP schools in treated years only. Female recipient percentage weighted by female enrollment. 
Table 3: Pre-treatment Trends

(a) Enrollment

\begin{tabular}{|c|c|c|c|c|c|c|}
\hline \multirow{5}{*}{$\begin{array}{l}\text { Outcome } \\
\text { Units } \\
\text { Grade } \\
\text { Sample }\end{array}$} & \multicolumn{6}{|c|}{ female enrollment } \\
\hline & \multicolumn{3}{|c|}{ level } & \multicolumn{3}{|c|}{ proportion } \\
\hline & Grade 7 & Grade 8 & Grade 9 & Grade 7 & Grade 8 & Grade 9 \\
\hline & $2 \overline{2003-2006}$ & $2003-2007$ & $2 \overline{2003-2008}$ & $2 \overline{2003-2006}$ & $2 \overline{2003-2007}$ & $\underline{2003-2008}$ \\
\hline & (1) & $(2)$ & $(3)$ & (4) & $(5)$ & (6) \\
\hline time & -0.1 & -0.4 & 2.2 & 0.01 & 0.01 & 0.01 \\
\hline & $(1.6)$ & $(1.1)$ & $(1.3)^{*}$ & $(0.006)^{* *}$ & $(0.004)^{* *}$ & $(0.004)^{* * *}$ \\
\hline time ${ }^{*}$ program & 6.0 & 0.9 & -1.6 & 0.01 & 0.01 & -0.01 \\
\hline & $(4.4)$ & $(3.0)$ & $(2.8)$ & $(0.01)$ & $(0.01)$ & $(0.01)$ \\
\hline$N$ & 366 & 471 & 577 & 363 & 463 & 534 \\
\hline$R^{2}$ & 0.02 & 0.00 & 0.02 & 0.45 & 0.44 & 0.47 \\
\hline Mean outcome & 69.2 & 65.3 & 57.6 & 0.47 & 0.46 & 0.44 \\
\hline
\end{tabular}

(b) Grade 9 exam

\begin{tabular}{|c|c|c|c|c|c|c|}
\hline & \multicolumn{2}{|c|}{ "female test-takers } & \multicolumn{4}{|c|}{ scores } \\
\hline & level & proportion & Math \& English & $\overline{\text { Math }}$ & English & Core \\
\hline & (1) & $(2)$ & $(3)$ & (4) & $(5)$ & (6) \\
\hline \multirow[t]{2}{*}{ time } & -1.7 & 0.01 & -0.01 & -0.01 & -0.01 & -0.01 \\
\hline & $(1.0)^{*}$ & $(0.003)^{* * *}$ & $(0.01)$ & $(0.01)$ & $(0.01)$ & $(0.01)$ \\
\hline \multirow[t]{2}{*}{ time ${ }^{*}$ program } & 1.2 & 0.003 & -0.004 & 0.001 & -0.01 & -0.01 \\
\hline & $(2.4)$ & $(0.01)$ & $(0.02)$ & $(0.03)$ & $(0.02)$ & $(0.03)$ \\
\hline$N$ & 516 & 69,952 & 30,603 & 30,603 & 30,603 & 30,423 \\
\hline$R^{2}$ & 0.02 & 0.01 & 0.12 & 0.10 & 0.11 & 0.15 \\
\hline Mean outcome & 61.2 & 0.44 & -0.19 & -0.12 & -0.20 & -0.24 \\
\hline
\end{tabular}

Sample is annual public school panel (Panel (a) and Panel (b), column 1) or Grade 9 student records (Panel (b) columns 2-6), Regions 2-6. All regressions include school fixed effects. Regressions for enrollment proportion weighted by enrollment. Outcome in Panel (b), column 2 is dummy variable for female. Standard errors clustered by school. * significant at $10 \%$; ** significant at $5 \%$; *** significant at $1 \%$. 
Table 4: Treatment Effects

(a) Enrollment

\begin{tabular}{|c|c|c|c|c|c|c|}
\hline \multirow{4}{*}{$\begin{array}{l}\text { Outcome } \\
\text { Units } \\
\text { Grade }\end{array}$} & \multicolumn{6}{|c|}{ female enrollment } \\
\hline & \multicolumn{3}{|c|}{ level } & \multicolumn{3}{|c|}{ proportion } \\
\hline & Grade 7 & Grade 8 & Grade 9 & Grade 7 & Grade 8 & Grade 9 \\
\hline & (1) & $(2)$ & $(3)$ & (4) & $(5)$ & (6) \\
\hline \multirow[t]{2}{*}{ treatment } & 10.5 & 8.7 & -7.5 & 0.02 & 0.01 & -0.02 \\
\hline & $(4.1)^{* *}$ & $(3.7)^{* *}$ & $(6.5)$ & $(0.01)$ & $(0.01)$ & $(0.01)$ \\
\hline$N$ & 1,022 & 1,022 & 1,022 & 1,019 & 1,004 & 961 \\
\hline$R^{2}$ & 0.04 & 0.06 & 0.06 & 0.41 & 0.41 & 0.45 \\
\hline Mean outcome & 71.9 & 67.7 & 60.0 & 0.49 & 0.49 & 0.46 \\
\hline Effect size as $\%$ of mean & $14.7 \%$ & $12.8 \%$ & $-12.5 \%$ & $3.4 \%$ & $2.6 \%$ & $-3.9 \%$ \\
\hline
\end{tabular}

(b) Grade 9 exam

\begin{tabular}{|c|c|c|c|c|c|c|}
\hline & \multicolumn{2}{|c|}{ female test-takers } & \multicolumn{4}{|c|}{ scores } \\
\hline & level & proportion & Math \& English & Math & English & $\underline{\text { Core }}$ \\
\hline & $(1)$ & $(2)$ & $(3)$ & (4) & $(5)$ & $(6)$ \\
\hline \multirow[t]{2}{*}{ treatment } & 4.2 & 0.001 & -0.09 & -0.06 & -0.09 & -0.05 \\
\hline & $(5.4)$ & $(0.01)$ & $(0.05)^{*}$ & $(0.08)$ & $(0.03)^{* * *}$ & $(0.06)$ \\
\hline$N$ & 934 & 121,413 & 55,398 & 55,398 & 55,398 & 55,113 \\
\hline$R^{2}$ & 0.03 & 0.01 & 0.09 & 0.09 & 0.09 & 0.11 \\
\hline Mean outcome & 61.3 & 0.46 & -0.21 & -0.12 & -0.22 & -0.24 \\
\hline
\end{tabular}

Sample is annual public school panel (Panel (a) and Panel (b), column 1) or Grade 9 student records (Panel (b) columns 2-6), Regions 2-6. All regressions include school and year fixed effects. Regressions for enrollment proportion weighted by enrollment. Outcome in Panel (b), column 2 is dummy variable for female. Standard errors clustered by school. * significant at $10 \%$; ** significant at $5 \%$; ** significant at $1 \%$. 


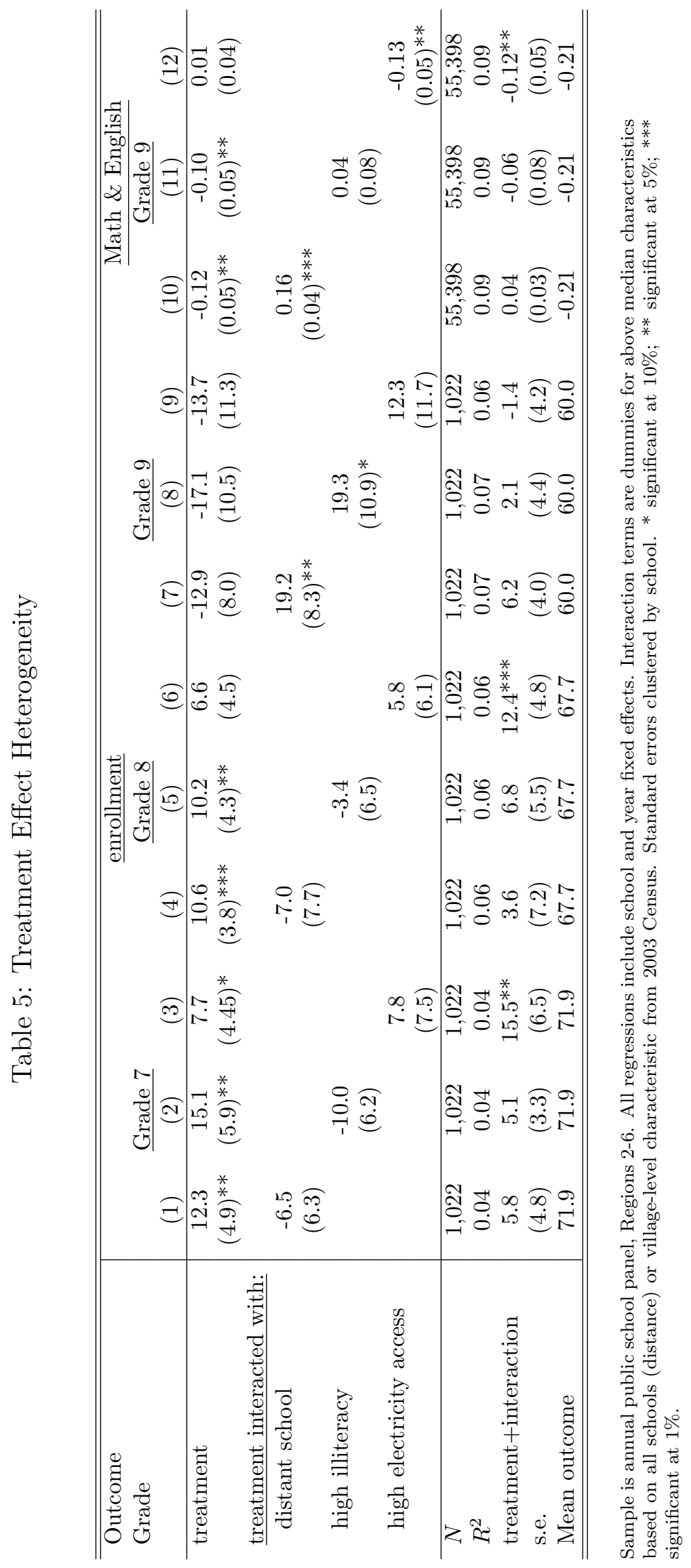


Table 6: Private school enrollment

\begin{tabular}{|c|c|c|c|c|c|c|}
\hline & \multicolumn{6}{|c|}{ female enrollment in private schools } \\
\hline & \multicolumn{3}{|c|}{ level } & \multicolumn{3}{|c|}{ private share in district } \\
\hline & Grade 7 & Grade 8 & Grade 9 & Grade 7 & Grade 8 & Grade 9 \\
\hline & $(1)$ & $(2)$ & $(3)$ & $(4)$ & $(5)$ & (6) \\
\hline \multicolumn{7}{|l|}{ Panel A } \\
\hline \multirow[t]{2}{*}{ any program school } & -10.8 & -9.0 & -11.9 & -0.01 & -0.01 & -0.02 \\
\hline & $(7.6)$ & $(5.4)$ & $(4.1)^{* * *}$ & $(0.01)$ & $(0.01)^{*}$ & $(0.01) * * *$ \\
\hline$R^{2}$ & 0.20 & 0.16 & 0.11 & 0.68 & 0.74 & 0.74 \\
\hline \multicolumn{7}{|l|}{ Panel B } \\
\hline$\%$ public enrollment & -7.0 & -6.3 & -9.9 & -0.03 & -0.02 & -0.03 \\
\hline in program schools & $(8.8)$ & $(5.6)$ & $(5.4)^{*}$ & $(0.03)$ & $(0.02)$ & $(0.02)$ \\
\hline$R^{2}$ & 0.20 & 0.16 & 0.11 & 0.71 & 0.79 & 0.76 \\
\hline$N$ & 346 & 346 & 346 & 346 & 346 & 345 \\
\hline Mean outcome & 9.9 & 7.6 & 6.5 & 0.05 & 0.04 & 0.04 \\
\hline
\end{tabular}

Sample is annual district panel, Regions 2-6. All regressions include district and year fixed effects. Outcome in columns (4)-(6) is proportion of private school share of female enrollment in district. Regressions for enrollment proportion weighted by district enrollment. Standard errors clustered by district. ${ }^{*}$ significant at $10 \%$; ** significant at 5\%; *** significant at $1 \%$. 
Table 7: Student composition

(a) Female grade repetition

\begin{tabular}{|c|c|c|c|c|c|c|}
\hline & \multicolumn{3}{|c|}{ level } & \multicolumn{3}{|c|}{ share of enrolled } \\
\hline & Grade 7 & Grade 8 & Grade 9 & Grade 7 & Grade 8 & Grade 9 \\
\hline & $(1)$ & $(2)$ & $(3)$ & (4) & $(5)$ & (6) \\
\hline \multirow[t]{2}{*}{ treatment } & 1.0 & -0.7 & 2.7 & 0.004 & -0.01 & 0.04 \\
\hline & $(2.8)$ & $(1.3)$ & $(2.0)$ & $(0.03)$ & $(0.02)$ & $(0.02)$ \\
\hline$N$ & 683 & 683 & 683 & 680 & 674 & 637 \\
\hline$R^{2}$ & 0.02 & 0.01 & 0.01 & 0.48 & 0.34 & 0.32 \\
\hline Mean outcome & 7.0 & 7.2 & 9.4 & 0.05 & 0.05 & 0.07 \\
\hline
\end{tabular}

(b) Grade 9 exam

\begin{tabular}{|c|c|c|c|c|c|}
\hline & $\frac{\text { test-taking } \%}{(1)}$ & $\frac{\text { No. subjects }}{(2)}$ & $\frac{\text { No. absent }}{(3)}$ & $\frac{\text { No. easy subjects }}{(4)}$ & $\frac{\text { easy subject } \%}{(5)}$ \\
\hline treatment & $\begin{array}{c}0.11 \\
(0.05)^{* *}\end{array}$ & $\begin{array}{l}-0.10 \\
(0.08)\end{array}$ & $\begin{array}{l}-0.04 \\
(0.04)\end{array}$ & $\begin{array}{l}-0.07 \\
(0.07)\end{array}$ & $\begin{array}{l}-0.004 \\
(0.01)\end{array}$ \\
\hline$N$ & 929 & 57,221 & 56,803 & 57,221 & 56,803 \\
\hline$R^{2}$ & 0.23 & 0.11 & 0.02 & 0.18 & 0.09 \\
\hline Mean outcome & 0.94 & 7.2 & 0.2 & 2.5 & 0.35 \\
\hline
\end{tabular}

Sample is annual public school panel, Regions 2-6. Unit is schools for panel (a) and panel (b), columns (1), students for panel (b), columns (2)-(5). All regressions include school and year fixed effects. Share of enrolloed repeaters is female repeaters divided by femal enrollment. Regressions for proportions weighted by enrollment. Test-taking \% is proportion of enrolled students taking Grade 9 exam. Easy subjects defined as above median pass rate in pre-treatment period (2003-2008). Easy \% is share of subjects taken that qualify as easy. Standard errors clustered by school. * significant at $10 \%$; ** significant at $5 \%$; $* * *$ significant at $1 \%$. 
Table 8: School quality

\begin{tabular}{|c|c|c|c|c|c|}
\hline & \multicolumn{3}{|c|}{ teachers } & \multicolumn{2}{|c|}{ pupil-teacher ratio } \\
\hline & total & female & $\%$ female & Grades 7-9 & Grades 1-9 \\
\hline & $(1)$ & $(2)$ & $(3)$ & $(4)$ & $(5)$ \\
\hline \multicolumn{6}{|c|}{ Panel A: treatment $=$ any program recipients } \\
\hline \multirow[t]{2}{*}{ treatment } & -4.3 & -1.7 & -0.04 & 6.9 & 2.8 \\
\hline & $(1.3)^{* * *}$ & $(0.4)^{* * *}$ & $(0.01)^{* * *}$ & $(2.4)^{* * *}$ & $(1.4)^{* *}$ \\
\hline$R^{2}$ & 0.27 & 0.14 & 0.04 & 0.05 & 0.19 \\
\hline \multicolumn{6}{|c|}{ Panel B: treatment = all years since program began } \\
\hline \multirow{2}{*}{ treatment } & 4.7 & 1.5 & 0.02 & -2.7 & -3.9 \\
\hline & $(1.8)^{* *}$ & $(0.6)^{* *}$ & $(0.02)$ & $(2.1)$ & $(1.1)^{* * *}$ \\
\hline$R^{2}$ & 0.27 & 0.14 & 0.04 & 0.04 & 0.20 \\
\hline$N$ & 1,014 & 1,014 & 1,014 & 1,014 & 1,014 \\
\hline Mean outcome & 23.6 & 4.6 & 0.17 & 22.8 & 12.1 \\
\hline
\end{tabular}

Sample is annual public school panel, Regions 2-6. All regressions include school and year fixed effects. Standard errors clustered by school. $*$ significant at $10 \% ; * *$ significant at $5 \% ; * * *$ significant at $1 \%$. 


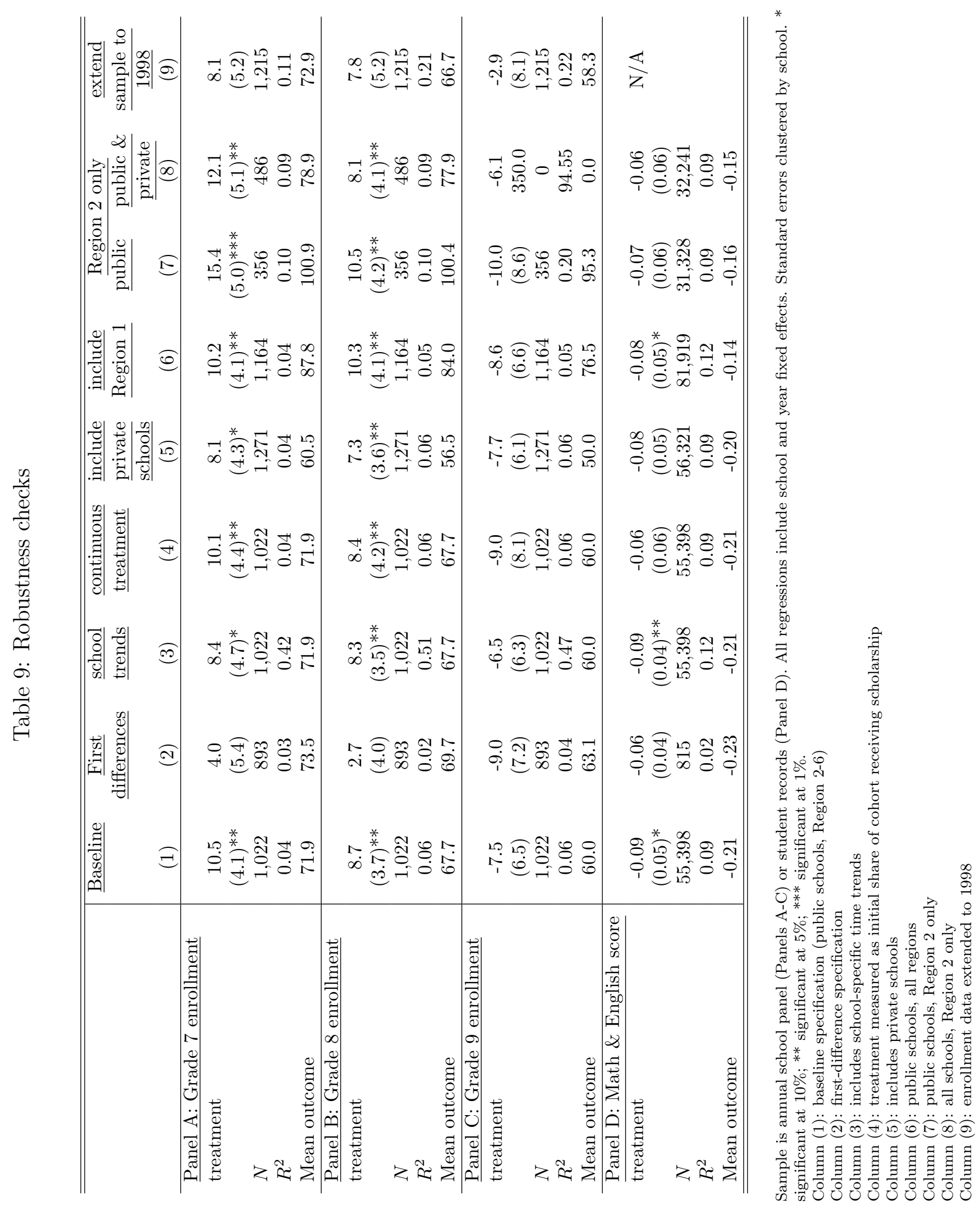


Table A1: Ratio of informal/formal school fees

\begin{tabular}{llrl}
\hline \hline Country & Level & Ratio & Source \\
\hline Cambodia & primary \& lower secondary & 10.7 & Education Watch $(2007)$ \\
Gambia & lower secondary & 11.1 & Daly $(2013)$ \\
Gambia & upper secondary & 4.9 & Daly $(2013)$ \\
India & primary & 6.7 & Kattan and Burnett $(2004)$ \\
Indonesia & primary & 8.1 & Kattan and Burnett $(2004)$ \\
Nigeria & primary & 7.2 & Lincove $(2009)$ \\
Nigeria & primary & 5.3 & Wiener $(2010)$ \\
Uganda & primary & 4.3 & Wiener $(2010)$ \\
Uganda & primary & 1.0 & Deininger $(2003)$ \\
Vietnam & primary & 24.0 & Kattan and Burnett $(2004)$ \\
Zambia & primary & 9.1 & Wiener $(2010)$ \\
\hline \hline
\end{tabular}

Authors' calculations from listed sources. 


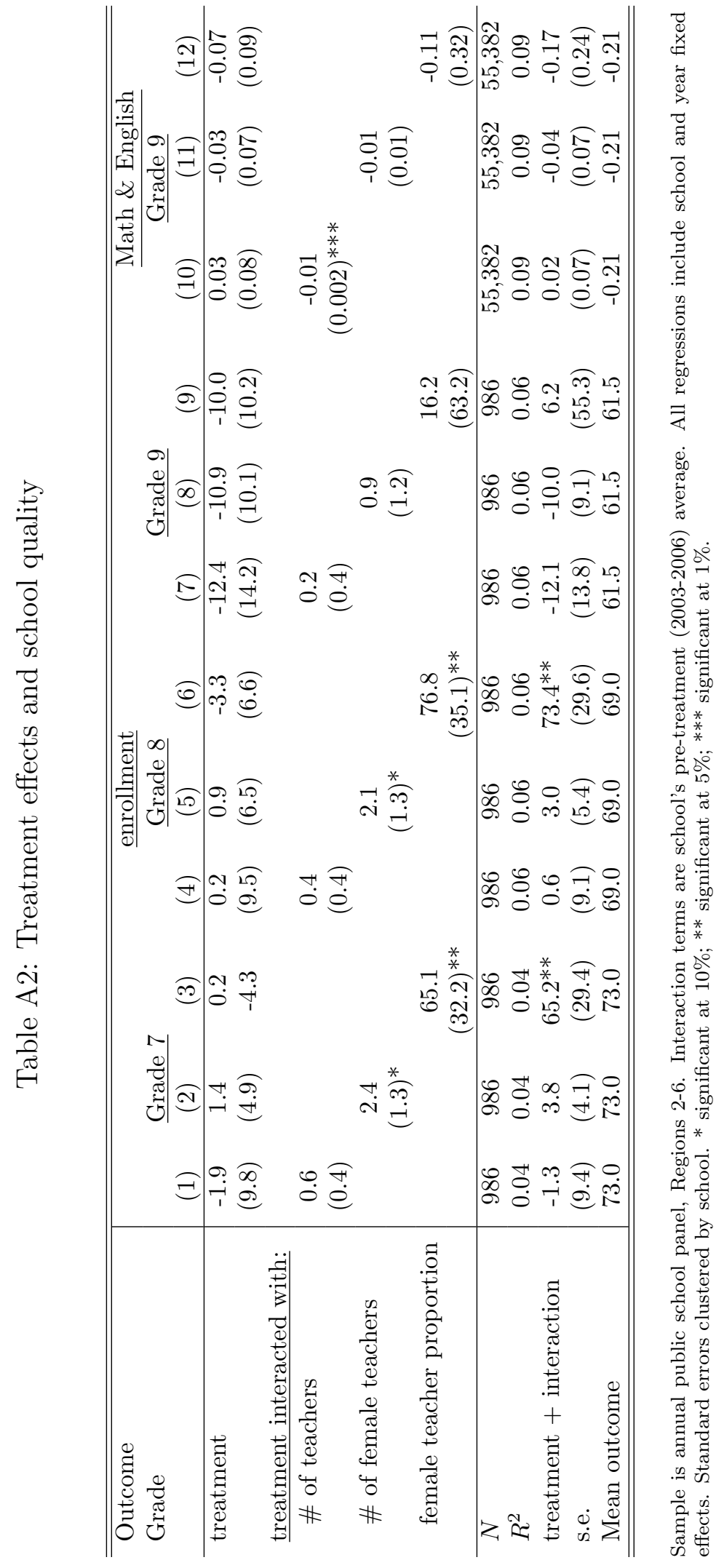




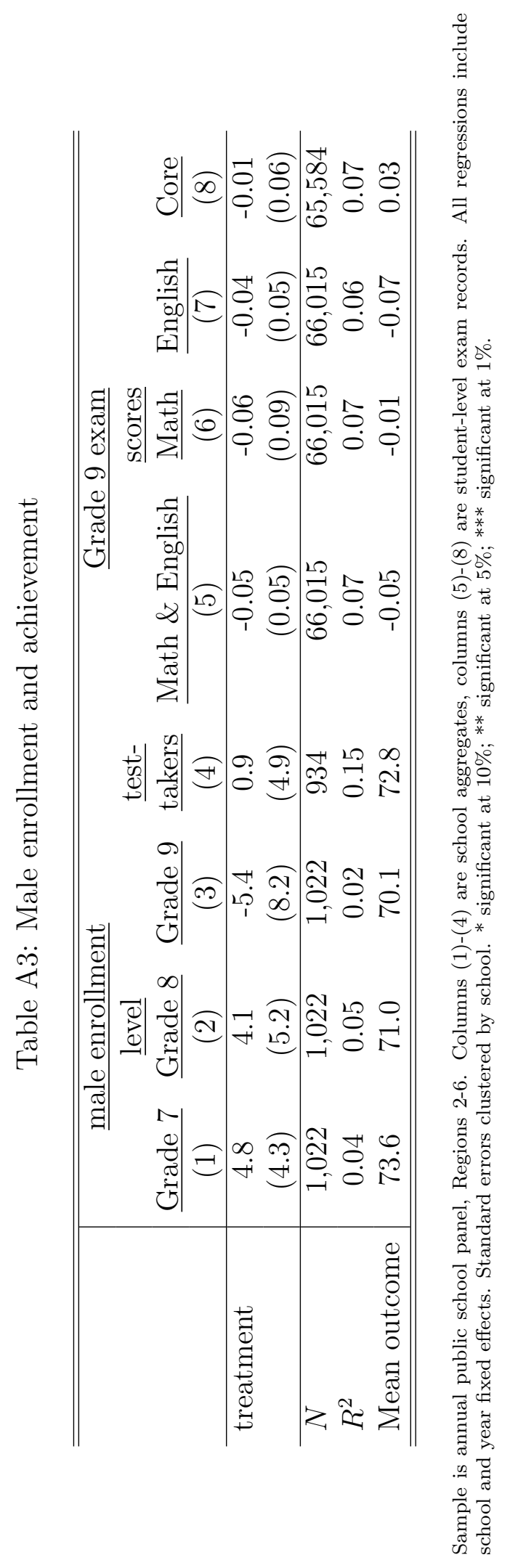

